\title{
Postpartum Başlangıç Olup Olmamasına Göre Bipolar Bozukluk Tanılı Kadın Hastaların Klinik Parametrelerinin Değerlendirilmesi
}

\section{Assessment of Clinical Parameters in Female Patients with Bipolar Disorder According to Presence or Absence of Postpartum-Onset}

iD Bahri İnce ${ }^{1}$ iD Kürşat Altınbaş

${ }^{1}$ Bakırköy Ruh ve Sinir Hastalıkları Eğitim ve Araştırma Hastanesi, Prof. Dr. Timuçin Oral Duygudurum Merkezi, İstanbul ${ }^{2}$ Selçuk Üniversitesi Tıp Fakültesi, Mazhar Osman Duygudurum Merkezi, Konya.

$\ddot{O} z$

Amaç: Farklı klinik görünümlere rağmen, postpartum psikoz epizotlarının bipolar bozukluk olduğuna dair klinik ve genetik çalışmalardan gelen güçlü kanıtlar vardır. Bu çalışmada postpartum başlangıç gösteren bipolar bozukluk tanılı hastalar ile en az bir doğum yapmış ve postpartum süreçte dönem yaşamamış olan bipolar bozukluk tanılı hastaların klinik özelliklerinin karşılaştırılması amaçlanmıştır.

Gereç ve Yöntem: Çalışma Bakırköy Prof. Dr. Mazhar Osman Ruh ve Sinir Hastalıkları Hastanesi ve Selçuk Üniversitesi Tıp Fakültesi Duygudurum Merkezlerinde bipolar bozukluk tanısı ile takip edilen hastalar ile yürütülmüştür. İlk hastalık belirtileri postpartum sürecin ilk 6 haftası içinde olan hastalar veri tabanlarından kontrol edilmiş ve bu hastalardan ulaşılabilen ve çalışmayı kabul eden 30 hasta çalışmanın ilk grubunu oluşturmak için ardışı olarak alınmıştır. İkinci grubu oluşturmak için en az bir doğum yapmış ve postpartum döneminde epizodu olmayan 30 kadın hasta ilk grubun yaşı ile birebir eşleştirilerek çalışmaya alınmıştır.

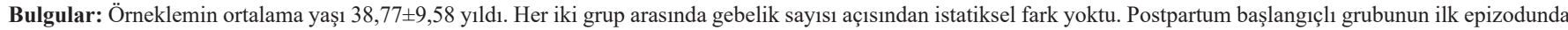
psikotik bulguların olma oranı \%33,3 ( $\mathrm{n}=10)$ iken diğer grupta bu oran $\% 10(\mathrm{n}=3)$ idi ve aradaki fark anlamlıydı $(\mathrm{x} 2=4,812$, p=0,028). Hastaların hastalık başlangıç yaş1 istatiksel olarak anlamlı çıkmasa da tip-1 hata oranı eşik düzeye yakındı ( $\mathrm{p}=0,074)$ ve hastalık başlangıç yaşı ortalaması postpartum başlangıç gösteren grupta yaklaşık 3,5 y1l daha erkendi.

Sonuç: Bu çalışma küçük örneklemine rağmen postpartum başlangıç ile bipolar bozukluğun klinik özelliklerini değerlendiren ilk çalışma olması açısından değerli bilgiler sunmaktadır. Daha büyük örneklemli araștırmalarda postpartum bașlangıç öyküsünün önemine ilișkin daha güçlü sonuçlar elde edilebilir.

Anahtar Kelimeler: Bipolar bozukluk, postpartum başlangıç, postpartum psikoz

Abstract

Objective: Despite diverse clinical presentations, there is strong evidence from clinical and genetic studies that episodes of postpartum psychosis are presentations of bipolar disorder. The present study was aimed to compare the clinical characteristics of patients with bipolar disorder who had postpartum-onset and patients with bipolar disorder who had at least one delivery and did not experience an episode in the postpartum period.

Materials and Methods: The study was carried out patients with bipolar disorder who were followed up at Bakırköy Prof. Dr. Mazhar Osman Hospital and Selcuk University Faculty of Medicine. Patients whose first symptoms were within six week period of time after delivery were checked from databases and 30 patients were accepted the study consecutively to compose the first group. To compose the second group, 30 female patients who had at least one delivery and didn't have an episode in postpartum period were included in study by matching the age of the first group.

Results: The mean age of the sample was $38.77 \pm 9.58$ years. There was no statistical difference between the two groups in terms of the number of pregnancies. The rate of psychotic symptoms in the postpartum-onset group was $33.3 \%(\mathrm{n}=10)$, while this rate was $10 \%(\mathrm{n}=3)$ in the other group, and the difference was significant $(\mathrm{x} 2=4.812$, $\mathrm{p}=0.028$ ). Although the onset-age of disease was not statistically significant, the type- 1 error rate was close to the threshold level ( $\mathrm{p}=0.074$ ), and the mean onset-age of disease was approximately 3.5 years earlier in the group with postpartum-onset.

Conclusion: This study provides helpful information as the first research to assess the clinical characteristics of bipolar disorder with postpartum-onset despite its small sample. More reliable results can be obtained regarding the importance of the postpartum-onset history in studies with larger samples.

Keywords: Bipolar disorder, postpartum onset, postpartum psychosis

Yazışma Adresi: Bahri İnce, Bakırköy Ruh ve Sinir Hastalıkları Eğitim ve Araştırma Hastanesi, Prof. Dr. Timuçin Oral Duygudurum

Merkezi, Bakırköy/ İstanbul

E-Posta: bahrince80@gmail.com

Alınma tarihi: 13.02.2021 / Kabul tarihi: 03.03.2021 / Yayımlanma tarihi: 20.09.2021

Postpartum Başlangıca Göre Bipolar Bozukluk Tanılı Hastaların Klinik

Genel Tip Derg 2021;31(3)266-269

Parametreleri - İnce ve Altınbaş 
Bipolar bozukluk (BB) mani, hipomani ve depresyon dönemleri ile karakterize, yineleyici ve kronik seyirli bir duygudurum bozukluğu olup yaşam boyu yaygınlığı yaklaşık olarak \%1-3 aralığında bildirilmektedir (1). Nüfus temelli çalışmalarda bipolar bozukluk karakteristik olarak erkeklerde ve kadınlarda yaklaşık olarak eşit oranda saptanmıştır ancak çalışmaların büyük kısmında bipolar II bozukluğun, hızlı döngülülük ve karma durumların kadınlarda daha sık olduğu bildirilmiştir (2). Bununla birlikte kadın hastalarda doğum, bipolar bozukluğun başlangıcı ve seyri üzerinde önemli bir etkiye sahiptir (3).

Farklı klinik görünümlere rağmen, postpartum psikoz epizotlarının bipolar bozukluğun sunumları olduğuna dair klinik ve genetik çalışmalardan gelen güçlü kanıtlar vardır (3). Danimarka doğum ve psikiyatrik başvuru kayıtları ile yapılan bir kohort çalışmasında, doğumdan sonraki ilk 28 günde ilk dönem bipolar manik depresif psikoz için rölatif risk 6,82 olarak saptanmıştır, bu rölatif risk şizofreni için ise 1'den az bulunmuştur (4). Yine Danimarka' da yapılan bir çalışmada doğum sonrası ilk psikiyatrik başvurusu olan kadınların 15 yıl süre zarfinda \%14' ünün bipolar bozukluk tanısı aldığı, bunun postpartum (PP) dönem dışındaki başvurulara göre yaklaşık 3 kat daha fazla olduğu belirtilmiştir (3).

Ailesinde postpartum psikoz veya bipolar bozukluk öyküsü olan kadınlar PP psikoz için risk altındadır (5). Yapılan bir çalışmada bipolar bozukluğu olan kadınların ailesinde postpartum psikoz öyküsü varsa bu kadınların \%74' ünde doğum sonrası psikoz saptanmıştır, bu oran aile öyküsü olmayan BB tanılı kadınlarda ise \%30 oranında saptanmıştır (6). Bununla birlikte geçmişte bipolar bozukluk tanısıyla hastane yatışı da postpartum psikoz gelişimini kuvvetle ön gördürmektedir ve bipolar bozukluğu olan kadınların doğumlarında $\% 25$ ila 40 oranında doğum sonrası psikoz gelişmektedir (6). Bununla birlikte geriye dönük uzun vadeli takip çalışmalarında ilk başlangıcı doğum sonrası psikozu veya manisi olan kadınların önemli bir kısmının, doğum sonrası dönem dışında manik ve depresif dönemlerle birlikte BB seyri yaşamadığını göstermiştir (7).

Postpartum dönemde duygudurum bozuklukları için önerilen tetikleyiciler, doğumdan sonra meydana gelen dramatik hormonal değişiklikler gibi biyolojik faktörlere ek olarak ilaç değişiklikleri, ebeveynliğe psikososyal uyum ve obstetrik komplikasyonları kapsar. Bugüne kadar, PP' nin etiyolojisinde yer alan en umut verici faktörler arasında primiparite, bağışıklık sistemi fonksiyonunun düzensizliği ve genetik faktörler yer almaktadır (8).

Psikiyatrik Genomik Konsorsiyum'un sürdürdüğü güncel genetik çalışmalarda genetik bir varyantın birden çok fenotipte (şizofreni, $\mathrm{BB}$, otizm, dikkat eksikliği hiperaktivite bozukluğu, depresyon) ortaya çıkması beklenenden daha yüksek oranda saptanmıştır (9). Bu durum güncel sınıflandırma sistemimizin psikiyatrik hastalıklarda etyopatogenezi yansıtmadığı yönünde yorumlanmaktadır. Postpartum psikoz için önemli bir fenotipik özellik psikiyatrik bozukluklar içinde birincil etiyolojik olayın bilindiği birkaç bozukluktan biri olmasıdır. Bipolar bozukluk başlangıcının sıklıkla kadın hastalarda reproprodüktif döneme denk gelmesinden dolayı postpartum başlangıç gösteren bipolar bozukluk tanılı kadın hastaları bu grubun dışında kalan diğer kadın bipolar bozukluk tanılı hastalardan ayırmak ve olası farklı klinik gidişatı belirlemek güçtür. Bugüne kadar yapılan araştırmalar öncelikle doğumun duygudurum dönemlerini nasıl tetikleyebileceğine odaklanmıştır. Bu çalışmada postpartum başlangıç gösteren BB tanılı hastalar ile en az bir doğum yapmış ve postpartum süreçte dönem yaşamamış olan BB tanılı hastaların klinik özelliklerinin karşılaştırılması amaçlanmıştır.

\section{Yöntem}

\section{Örneklem Seçimi}

Bakırköy Prof. Dr. Mazhar Osman Ruh Sağlığı ve Sinir Hastalıkları Eğitim ve Araştırma Hastanesi Timuçin Oral Duygudurum Merkezi'nde ve Selçuk Üniversitesi Tıp Fakültesi Mazhar Osman Duygudurum Merkezi'nde takip ve tedavisi yürütülmekte olan, en az iki bağımsız klinisyen tarafından Amerikan Psikiyatri Birliği'nin Ruhsal Hastalıkların Tanısal ve Sayımsal El Kitabı (DSM-5)'na göre BB tanısı konmuş ve remisyonda olan hastalardan araştırmaya katılmayı kabul edenler çalışmaya ardışık olarak dâhil edilmiştir.

\section{İşleyiş}

İlk hastalık belirtileri postpartum sürecin ilk 6 haftası içinde olan kadın bipolar bozukluk tanılı hastalar veri tabanlarından kontrol edilmiş ve bu hastalardan ulaşılabilen ve çalışmayı kabul eden 30 hasta çalışmanın ilk grubunu oluşturmak için ardışık olarak alınmıştır. İkinci grubu oluşturmak için en az bir doğum yapmış ve postpartum döneminde epizodu olmayan 30 kadın bipolar bozukluk tanılı hasta ilk grubun yaşı ile birebir eşleştirilerek çalışmaya alınmıştır. Katılımcıların remisyon durumunun değerlendirilmesi amacıyla daha önceden Türkçe formunun güvenirliği ve geçerliği gösterilmiş olan Young Mani Derecelendirme Ölçeği (10) ve Hamilton Depresyonu Derecelendirme Ölçeği (11) kullanılmıştır. Remisyon ölçütleri en az 2 aylık süreçte Young Mani Derecelendirme Ölçeği'nden 6 ve 17-maddeli Hamilton Depresyon Derecelendirme Ölçeği'nden 8 puanın altında olma şeklinde belirlenmiştir. Araştırmaya dâhil edilen hastaların klinik ve sosyodemografik bilgileri hastane tıbbi kayıtlarından ve hastalar ile görüşmeler sırasında doldurulmuştur. Hastalardan klinik bilgiler olarak: bipolar bozukluk tipi, hastalık başlangıç yaşı, ilk epizot türü, ilk epizotun psikotik özellik gösterip göstermediği, epizotlarda karma belirtilerin varlığı, hastaneye yatış sayısı, birinci ve ikinci derecede akrabalarda bipolar bozukluk tanısının varlığı, klinik gidişatın göstergesi olarak manik, depresif ve toplam epizot dansitesi (epizot sayısi/hastalık süresi) ve eşlik eden bedensel rahatsızlıklar alınmıştır. Araştırma için Selçuk Üniversitesi Tip Fakültesi'nden 2021/36 karar no ile yerel etik kurul onay1 alınmıştır. Tüm deneklerden bu çalışma için aydınlatılmış onam formu toplanmıştır.

\section{İstatistik Yöntem}

İstatistiksel analizler için SPSS (Statistical Package for the Social Sciences) 20.0 versiyonu kullanılmıştır. Sürekli değişkenlerin dağılımının normale yakın olup olmadığı histogram ve KolmogorovSmirnov testi ile araştııılmıştır. Tanımlayıcı istatistikler sürekli değişkenler için ortalama \pm standart sapma veya ortanca (minumum - maksimum) olarak, kategorik değişkenler ise olgu sayısı ve (\%) olarak gösterilmiştir. Parametrik test varsayımları sağlanmadığından iki grup karşılaştırmalarında Mann Whitney U testi kullanıldı. Gruplar arasında kategorik değişkenler bakımından farklılık olup olmadığı ki kare testi veya Fisher kesin testi ile araştırıldı. 


\section{Bulgular}

Yaşları birebir eşlenmiş olan örneklemin ortalama yaşı $38,77 \pm 9,58$ yıldı. Postpartum başlangıçlı BB grubunda ortanca gebelik sayısı 2 (minumum:1, maksimum:10), postpartum başlangıcı olmayan BB grubunda ortanca gebelik sayıs1 2 (minumum:1, maksimum:6) idi ve 2 grup arasında gebelik sayısı açısından istatiksel fark yoktu $(\mathrm{Z}=-0,361, \mathrm{p}=0,718)$. Hastaların sosyodemografik verileri tablo- 1 de verilmiş olup gruplar arasında bu veriler açısından istatistik olarak fark saptanmadi.

PP başlangıç göstermeyen BB grubunun ortalama hastalık başlangıç yaşı 27,2 yıl, PP başlangıçlı BB grubunun ortalama hastalık başlangıç yaşı ise 23,6 y1l olarak saptandı ancak iki grup arasında istatistiksel farklılık saptanmadı. Postpartum başlangıçlı BB grubunun ilk epizodunda psikotik bulguların olma oran $\% 33,3(n=10)$ iken diğer grupta bu oran $\% 10(n=3)$ idi ve aradaki fark anlamlıd $1\left(x^{2}=4,812\right.$, $\mathrm{p}=0,028$ ). Manik epizot dansitesi, depresif epizot dansitesi ve toplam epizot dansitesi postpartum başlangıçlı olmayan BB grubunda yüksek bulunsa da aradaki fark anlamlı bulunmadı. Diğer klinik verilerin karşılaştırılması tablo-2 de gösterilmiştir. PP başlangıçlı BB grubunda $19(\% 63,3)$ hastanın eşlik eden bir bedensel hastalığı yok iken diğer grupta $18(\% 60)$ hastanın ek tanısı yoktu. Hastaların bedensel hastalıkları tablo-3 de özetlenmiştir.

Tablo 1. Sosyo-demografik verilerin dağılımı

\begin{tabular}{|c|c|c|c|c|}
\hline & $\begin{array}{l}\text { Postpartum Başlayan } \\
\text { BB(n=30) }\end{array}$ & $\begin{array}{l}\text { Postpartum } \\
\text { Başlamayan } \\
\text { BB }(n=30)\end{array}$ & $\mathrm{Z} / \mathrm{x}^{2}$ & $\mathrm{p}$ \\
\hline Yaş (yıl) (orttSS.D) & $38,77 \pm 9,58$ & $38,77 \pm 9,58$ & 0 & 1 \\
\hline Eğitim (yıl) (ortıS.D) & $8,4 \pm 3,77$ & $8,1 \pm 3,96$ & 0,56 & 0,57 \\
\hline $\begin{aligned} & \text { Medeni Durum, } \mathrm{n}(\%) \\
& \\
&$\[ \quad \text { Evli } \]$ \\
& \vdots \text { Boşanmış } \\
& \text { Dul }\end{aligned}$ & $\begin{array}{l}20(\% 66,7) \\
8(\% 26,6) \\
2(\% 6,7)\end{array}$ & $\begin{array}{l}25(\% 83,3) \\
4(\% 16,6) \\
1(\% 3,3)\end{array}$ & 2,22 & 0,33 \\
\hline 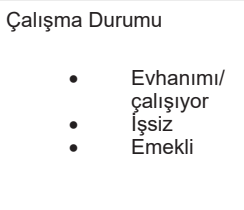 & $\begin{array}{l}27(\% 90) \\
2(\% 6,7) \\
1(\% 3,3)\end{array}$ & $\begin{array}{l}30(\% 100) \\
0 \\
0\end{array}$ & 3,16 & 0,21 \\
\hline Çocuk Sayısı (ortıS.D) & $1,8 \pm 1,32$ & $1,97 \pm 1,13$ & 0,82 & 0,41 \\
\hline Gebelik Sayısı (ort $\pm S . D)$ & $2,47 \pm 1,69$ & $2,53 \pm 1,41$ & 0,72 & 0,72 \\
\hline
\end{tabular}

Tablo 2. Klinik parametrelerin dağılımı

\begin{tabular}{|c|c|c|c|c|}
\hline & $\begin{array}{l}\text { Postpartum } \\
\text { Başlayan } \\
\mathrm{BB}(\mathrm{n}=30)\end{array}$ & $\begin{array}{l}\text { Postpartum } \\
\text { Başlamayan } \\
\text { BB }(n=30)\end{array}$ & $z / x^{2}$ & $\mathrm{p}$ \\
\hline Hastalık Süresi (yıl) (ortıS.D) & $15,13 \pm 7,8$ & $11,57 \pm 6,97$ & $-1,821$ & 0,069 \\
\hline Hastalık Başlangıç Yaşı (yıl), (orttS.D) & $23,63 \pm 4,93$ & $27,2 \pm 8,15$ & $-1,787$ & 0,074 \\
\hline $\begin{array}{l}\text { Bipolar Bozukluk Tipi, n(\%) } \\
\begin{array}{c}\text { - } \quad \text { Tip } 1 \\
\text { Tip 2 }\end{array}\end{array}$ & $\begin{array}{l}25(\% 83,3) \\
5(\% 16,7)\end{array}$ & $\begin{array}{l}21(\% 70) \\
9(\% 30)\end{array}$ & 1,49 & 0,22 \\
\hline $\begin{array}{l}\text { Illk Epizot, } \mathrm{n}(\%) \\
\qquad \quad \begin{array}{l}\text { Mani/hipomani } \\
\text { Depresyon }\end{array}\end{array}$ & $\begin{array}{l}13(\% 43,3) \\
17(\% 56,7)\end{array}$ & $\begin{array}{l}8(\% 26,7) \\
22(\% 73,3)\end{array}$ & 1,832 & 0,176 \\
\hline
\end{tabular}

Postpartum Başlangıca Göre Bipolar Bozukluk Tanılı Hastaların Klinik Parametreleri - İnce ve Altınbaş

\begin{tabular}{|c|c|c|c|c|}
\hline $\begin{array}{c}\text { İlk Epizotta } \text { Psikoz, n(\%) } \\
\begin{array}{cc}\text { • } & \text { Var } \\
\text { Yok }\end{array}\end{array}$ & $\begin{array}{l}10(\% 33,3) \\
20(\% 66.7)\end{array}$ & $\begin{array}{l}3(\% 10) \\
27(\% 90)\end{array}$ & 4,812 & 0,028 \\
\hline $\begin{array}{c}\text { Karma Özellikli Epizot } \\
\text { • } \quad \text { Var } \\
\text { Yok }\end{array}$ & $\begin{array}{l}5(\% 16,7) \\
25(\% 83,3)\end{array}$ & $\begin{array}{l}1(\% 3,3) \\
29(\% 96,7)\end{array}$ & 2,963 & 0,195 \\
\hline 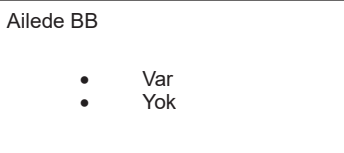 & $\begin{array}{l}15(\% 50) \\
15(\% 50)\end{array}$ & $\begin{array}{l}14(\% 46,7) \\
16(\% 53,3)\end{array}$ & 0,067 & 0,796 \\
\hline Hastaneye yatış sayısı, (ortıS.D) & $1,86 \pm 1,71$ & $2,83 \pm 2,78$ & $-1,466$ & 0,143 \\
\hline Manik Epizot Dansitesi, (ort $\pm S . D$ ) & $0,19 \pm 0,22$ & $0,38 \pm 0,6$ & $-0,84$ & 0,401 \\
\hline Depresif Epizot Dansitesi, (ort $\pm S . D)$ & $0,24 \pm 0,25$ & $0,43 \pm 0,55$ & $-1,798$ & 0,072 \\
\hline Toplam Epizot Dansitesi, (ort士S.D) & $0,33 \pm 0,29$ & $0,46 \pm 0,56$ & $-1,773$ & 0,076 \\
\hline
\end{tabular}

Tablo 3. Bedensel komorbid hastalıkların dağılımı

\begin{tabular}{|l|l|l|}
\hline $\begin{array}{l}\text { Eştanılar } \\
n(\%)\end{array}$ & $\begin{array}{l}\text { Postpartum Başlayan } \\
\text { BB(n=30) }\end{array}$ & $\begin{array}{l}\text { Postpartum Başlamayan } \\
\text { BB }(n=30)\end{array}$ \\
\hline Hipotiroidi & $5(\% 16,7)$ & $6(\% 20)$ \\
\hline Diabet & $2(\% 6,7)$ & $2(\% 6,7)$ \\
\hline Hipertansiyon & 0 & $1(\% 3,3)$ \\
\hline Astım & $1(\% 3,3)$ & $1(\% 3,3)$ \\
\hline PCOS & 0 & $2(\% 6,7)$ \\
\hline SLE & $1(\% 3,3)$ & 0 \\
\hline Behçet Hastalığı & $1(\% 3,3)$ & $1(\% 3,3)$ \\
\hline FMF & $1(\% 3,3)$ & 0 \\
\hline
\end{tabular}

\section{Tartışma}

Postpartum başlangıç gösteren BB tanılı hastalar ile en az bir doğum yapmış ve postpartum süreçte epizot yaşamamış olan BB tanılı hastaların klinik özelliklerinin karşılaştırılması amaçlanan bu çalışmada güncel yaşlar birebir eşlenik olarak alınmıştır. Hastaların hastalık başlangıç yaşı ve hastalık süresi istatiksel olarak anlamlı çıkmasa da tip-1 hata oranı eşik düzeye yakındı (sırasıyla p değerleri $0,074 ; 0,069)$ ve hastalık başlangıç yaşı ortalaması PP başlangıç gösteren grupta yaklaşık 3,5 yıl daha erken olarak 23,63 yıl olarak bulundu. Hastalık başlangıç yaşı kompleks genetik hastalıklarda hastalık genlerinin tanımlanması için gerekli fenotipik ayrımda önemli bir rol oynayabilir. Bunun için BB'nin başlangıç yaşı son zamanlarda klinik sınıflandırma için bir araç olarak önerilmiştir (12). Bipolar bozukluğun başlangıç yaşı için genel olarak bimodal dağılımdan bahsedilse de çocukluk çağında görülen $\mathrm{BB}$ verilerinin artmasıyla yakın zamanlı çalışmalarda trimodal dağılım öne sürülmektedir (13). Avrupa ve Amerika'dan tip 1 BB tanılı olgularla yapılan geniş örneklemli bir çalışmada hastalık başlangıç yaşı dönemleri ortalamaları erken başlangıç için Avrupa'da 19 $\pm 2,7$ yıl,

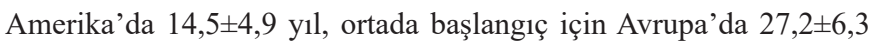

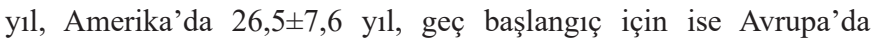

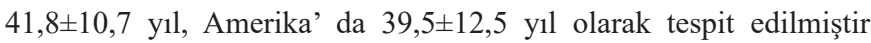
(13). Çalışmamızda her iki grupta ortada başlangıç yaş dağılımına uymaktadır. Bu postpartum başlangıçlı olan grup için yasal evlilik yaşı ve kültürel faktörler düşünüldüğünde beklenen bir durumdur, ancak PP başlangıcı olmayan grubun istatistiksel olarak anlam sınırına yakın olarak yaklaşık 3,5 yıl ileride olması dikkat çekmektedir. Bu durum PP başlangıcı olmayan grupta çocukluk ve/veya ergenlik döneminde başlangıç gösteren hastaların hastalık nedeniyle evlenmemeleri ya da 
tedavi nedeniyle gebelik istememeleri veya ertelemeleri nedeniyle çalışma dışında kalmaları sonucu ortaya çıkmış olabilir. Yine PP başlangıçlı grupta hastalık başlangıcı çok net bilinebilirken, PP başlangıcı olmayan grupta belirtilerin ortaya çıkmasından sonra tedavi başvurusuna kadar geçen uzun süreler hastalık başlangıç yaşını belirlemede bir gecikmeye neden olabilir (14). Yakın zamanda yapılan bir meta-analizde ailesinde duygudurum bozukluğu olan bipolar olgularda sadece hastalık başlangıç yaşının daha erken olma eğiliminde olduğu (meta-regresyon katsayıs1:-0,07, p:0,06) ve ailede duygudurum bozukluğu öyküsü olan hastaların oranındaki \%10'luk bir artışın ortalama hastalık başlangıç yaşını yaklaşık 1 yıl öne çektiği gösterilmiştir (15). Ancak çalışmamızda her iki grupta da ailede BB varlığ 1 yaklaşık olarak \%50 ile benzer olarak bulunmuştur.

Çalışmamızda PP başlangıcı olan grubun ilk epizotunda psikoz olması anlamlı olarak yüksek bulundu (\%33,3' e karş1 \%10). Duygudurum bozukluklarında psikozun bir durum özelliği olması nedeniyle bu konudaki çalışmalar daha çok ilk epizot psikoz ve çocukluk çă̆ BB çalışmalarında yer bulmaktadır. BB ile ilgili çalışmalarda ise daha çok psikozun duygudurumla uyumlu olup olmaması konusuna yoğunlaşılmıştır. İlk epizot manide psikotik semptomların prevalansı özel olarak çalışılmamıştır, yayınlanmış verilerden elde edilen tahminler, vakaların\%63-88' inde mevcut olduklarını göstermektedir (16). Yapılan bir çalışmada ilk epizot psikozu olan hastaların \%37' sinde daha sonra duygudurum epizotları görülürken, sonraki 48 ay içinde başka psikotik epizot görülmemiştir (17). Genel olarak, psikotik semptomların varlığı çocuk ve ergen başlangıçlı BB tanılı hastalarda yetişkin başlangıçlı olanlara göre daha sık görünmektedir (17-18). Ayrıca manik dönemde daha sık psikotik özellik görülmektedir (16) Çalışmamızda PP başlangıç gösteren grubun istatistiksel olarak anlamlı olmasa da daha yüksek oranda tip-1 BB tanılı hasta içermesi (\%83,3' e karş1 \%70) ve ilk epizot olarak daha yüksek oranda mani görülmesi (\%43,3’ e karş1 \%26,7), bu grupta daha yüksek oranda ilk epizotta psikotik özellik olmasını etkilemiş olabilir. Bipolar bozukluk epizotlarında psikotik belirtilerin olmasının prognoza etkisi ise net değildir (19). Çalışmamızda hastalık gidişatının bir göstergesi olarak kullandığımız epizot dansiteleri her iki grupta da benzer bulunsa da depresif epizot dansitesinin ve toplam epizot dansitesinin tip-1 hata oranı eşik düzeye yakındı (sırasıyla p değerleri 0,072; 0,076) ve her iki oran ortalaması PP başlangıç göstermeyen grupta yüksekti. Çalışmamızın verileri değerlendirildiğinde sadece ilk epizotta psikotik özellikler değerlendirilmiş olup hastalığın diğer epizotlarındaki psikotik belirtiler değerlendirilmemiştir. İlk epizotta psikotik belirtilerin olması hastalık prognozunun bir göstergesi olan epizot dansitesine etki etmiyor olabilir ancak bu verinin daha farklı dizaynda, bipolar bozukluğun alt tipleri açısından homojen olan gruplarda ve daha yüksek örneklemle çalışılması gerekmektedir.

Bipolar bozukluk başlangıcının sıklıkla kadın hastalarda reproprodüktif döneme denk gelmesinden dolayı postpartum başlangıç gösteren bipolar bozukluk tanılı kadın hastaları bu grubun dışında kalan diğer kadın bipolar bozukluk tanılı hastalardan ayırmak beraberinde bazı metodolojik k1sitlılıkları da getirmektedir. Bu çalışmada bir ayrım yapabilmek için en az bir doğum yapmış ve postpartum dönemde epizot yaşamamış BB tanılı hastalar alınmıştır ancak bu hastaların tedavisi ve takibi gebelik ve lohusalık döneminde de devam etmiş olabilir, tedavinin varlığ koruma sağlamış olabilir. Bu çalışma özeline yönelik kısıtlılıklar ise görece örneklemin küçüklüğü, verilerinin geriye dönük olarak tespit edilip, kesitsel olarak değerlendirilmiş olması ve özelleşmiş duygudurum merkezlerinden düzenli takip edilen bir örneklemde gerçekleştirildiğinden genel hasta topluluğunu yansıtmıyor olması olarak sayılabilir. Bununla beraber araştırmamız, BB tanılı hastalarda PP başlangıç ile bipolar bozukluğun klinik özelliklerini değerlendiren ilk çalışma olması açısından değerli bilgiler sunmaktadır. Çok merkezli yapılacak daha büyük örneklemli yeni araştırmalarda PP başlangıç öyküsünün BB hastalarındaki önemine ilişkin daha güçlü sonuçlar elde edilebilecektir.

\section{Kaynaklar}

1.Merikangas KR, Jin R, He JP, et al. Prevalence and correlates of bipolar spectrum disorder in the world mental health survey initiative. Arch Gen Psychiatry 2011;68:241251 .

2.Diflorio A, Jones I. Is sex important? Gender differences in bipolar disorder. Int Rev Psychiatry 2010;22:437-452.

3.Munk-Olsen T, Laursen TM, Meltzer-Brody S, Mortensen PB, Jones I. Psychiatric disorders with postpartum onset: possible early manifestations of bipolar affective disorders. Arch Gen Psychiatry 2012;69:428-434

4.Terp IM, Mortensen PB. Post-partum psychoses. Clinical diagnoses and relative risk of admission after parturition. Br J Psychiatry 1998;172:521-526.

5.Harlow BL, Vitonis AF, Sparen P, et al. Incidence of hospitalization for postpartum psychotic and bipolar episodes in women with and without prior prepregnancy or prenatal psychiatric hospitalizations. Arch Gen Psychiatry 2007;64:42-48.

6.Jones I, Craddock N. Familiality of the puerperal trigger in bipolar disorder: results of a family study. Am J Psychiatry 2001;158:913-917.

7.Chaudron LH, Pies RW: The relationship between postpartum psychosis and bipolar disorder: a review. J Clin Psychiatry 2003; 64:1284-1292.

8.Jones I, Chandra PS, Dazzan P, Howard LM. Bipolar disorder, affective psychosis, and schizophrenia in pregnancy and the post-partum period. Lancet 2014;384:1789-1799.

9.O'Donovan MC. What have we learned from the Psychiatric Genomics Consortium. World Psychiatry 2015;14:291-293.

10.Karadağ F, Oral ET, Yalçın FA, Erten E. Young Mani Derecelendirme Ölçeğinin Türkiye'de geçerlik ve güvenilirliği. Turk Psikiyatr Derg 2002;13:107-14.

11.Akdemir A, Dönbak SÖ, Dağ İ ve ark. Hamilton Depresyon Derecelendirme Ölçeği (HDDÖ)'nin geçerliliği, güvenilirliği ve klinikte kullanımı. Psikiyatri Psikoloji Psikofarmakoloji Dergisi: 3P 1996;4: 251-9.

12.Geoffroy PA, Etain B, Scott J, et al. Reconsideration of bipolar disorder as a developmental disorder: Importance of the time of onset. J Physiol Paris. 2013;107:278285 .

13.Bellivier F, Etain B, Malafosse A, et al. Age at onset in bipolar I affective disorder in the USA and Europe. World J Biol Psychiatry 2014;15:369-76.

14.Altınbaș K. Duygudurum Bozuklukları Tanı ve Tedavisi. 1st ed. Konya: Bahçıvanlar Basım, 2020:1-13.

15.Dagani J, Baldessarini RJ, Signorini G, et al. The age of onset of bipolar disorders. In de Girolamo G, McGorry PD, Sartorius N, editors, Age of onset of mental disorders: etiopathogenetic and treatment implications. Cham: Springer, Springer Nature. 2019: 75110 .

16.Conus P, McGorry PD. First-episode mania: a neglected priority for early intervention. Aust N Z J Psychiatry 2002;36:158-72.

17.Carlson GA. Affective Disorders and Psychosis in Youth. Child Adolesc Psychiatr Clin N Am 2013;22:569-80.

18.McClellan J, Kowatch R, Findling RL; Work Group on Quality Issues. Practice parameter for the assessment and treatment of children and adolescents with bipolar disorder. J Am Acad Child Adolesc Psychiatry 2007;46:107-25.

19.Canuso CM, Bossie CA, Zhu Y, Youssef E, Dunner DL. Psychotic symptoms in patients with bipolar mania. J Affect Disord 2008;111:164-169.

Postpartum Başlangıca Göre Bipolar Bozukluk Tanılı Hastaların Klinik Parametreleri - İnce ve Altınbaş 